\title{
White Paper: functionality and efficacy of wrist protectors in snowboarding - towards a harmonized international standard
}

\author{
Frank I. Michel · Kai-Uwe Schmitt • \\ Richard M. Greenwald • Kelly Russell • \\ Frank I. Simpson · David Schulz $\cdot$ Mike Langran
}

Published online: 14 March 2013

(C) The Author(s) 2013. This article is published with open access at Springerlink.com

\begin{abstract}
The wrist is the most frequently injured body region among snowboarders. Studies have shown that the risk of sustaining a wrist injury can be reduced by wearing wrist protection. Currently, there are a wide variety of wrist protection products for snowboarding on the market that offer a range of protective features. However, there are no minimum performance standards for snowboarding wrist protectors worldwide. The International Society for Skiing Safety convened a task force to develop a White Paper to evaluate the importance and necessity of a minimum performance for all wrist protectors used in snowboarding. The White Paper outlines the need for a general framework
\end{abstract}

F. I. Michel ( $\square)$

Sports Division, Research Department, bfu - Swiss Council

for Accident Prevention, Hodlerstrasse 5a, 3011 Berne,

Switzerland

e-mail: f.michel@bfu.ch

\section{K.-U. Schmitt}

Institute for Biomedical Engineering,

University and ETH Zürich, Zurich, Switzerland

K.-U. Schmitt

AGU, Zurich, Switzerland

R. M. Greenwald · F. I. Simpson

Simbex, Lebanon, NH, USA

K. Russell

Departments of Pediatrics and Community Health Sciences, University of Manitoba, Winnipeg, Canada

D. Schulz

Office for Sports Injury Analysis, ARAG Sports Insurance,

Düsseldorf, Germany

M. Langran

Aviemore Medical Practice, Aviemore, Scotland, UK for a harmonized international standard and reviews the existing evidence. Therefore, this White Paper may serve as a common base for future discussions. The broader goal of developing and implementing such a standard is to reduce the incidence and the severity of wrist injuries in snowboarding without increasing the risk of adverse events, such as upper arm or shoulder injury. The European standard for inline skating wrist protectors (EN 14120) can serve as a starting point for efforts related to a standard for snowboard wrist protectors, but certain modifications to the standard would be required. It is hypothesized that implementation of a snowboarding wrist protector standard would result in fewer and less severe wrist injuries in the sport and could translate into more riding days for healthy snowboarders and significant health-care costs savings.

Keywords Injury · Wrist · Protector · Snowboarding · Standard · PPE · White Paper

\section{Introduction, objectives and method}

\subsection{Introduction}

Snowboarding is relatively new compared with alpine skiing. The origin of snowboarding lies in surfing and skiing [1]. Anecdotes tell of early experiments with a stand-up sled in the 1920s in Europe [2]. The first commercial snowboard was launched in 1965, when Sherman Poppen introduced the "Snurfer" (snow-surfer) [1-3]. In the 1970s, snowboard pioneer Dimitrije Milovich offered his "Winterstick", which is considered to be the first modern snowboard [2, 4]. Before this, few people considered riding a snowboard in high alpine terrain and on slopes with more than $50^{\circ}$ inclination [5]. 
Between 1970s and 1980s, snowboarding gained international popularity $[4,6]$. Snowboarding was a demonstration sport during the 1994 Olympic Winter Games in Lillehammer, Norway [7]. During the 1998 Olympics in Nagano, Japan, snowboarding debuted as an official Olympic sport in the disciplines of half-pipe and parallel giant-slalom racing [6, 7]. Currently, Olympic snowboarding disciplines include half-pipe, snowboard cross, and parallel giant-slalom racing for both men and women.

There are an estimated 10-15 million riders worldwide and it is particularly popular among adolescents and younger adults $[6,8,9]$. However, evidence suggests that the average age of snowboarders is increasing [10]. During the $2009 / 10$ winter season, there were approximately 8.2 million in the United States, compared with 11.5 million alpine skiers and 4.5 million cross-country skiers [11]. This represented a $20 \%$ increase in snowboarders (from 6.8 million) in the US and an $11 \%$ decrease in alpine skiers (from 10.4 million) compared with the 2006/07 winter season [11]. A higher proportion of the US snowboard population were male (66\%), which is similar to alpine skiers $(60 \%)$ [11]. Snowboarders tend to be younger than skiers, with approximately $54 \%$ between 6-24 years old and $31 \%$ between 6 and 17 years old [11]. In addition, the number of snowboarders has increased in Canada from 1.2 million in 2004/05 to 1.6 million in 2009/10, representing an increase of $33 \%$ [10]. Snowboarding is also very popular in Europe. An estimated 438,000 people snowboard every year in Switzerland [12]. Around $5 \%$ of the Swiss population aged 15-75 years and $11 \%$ of children and adolescents (10-14 years) also participate annually [12-15]. The Mach Consumer Survey 2011 declared that $5 \%$ of the Swiss population ( $>14$ years) snowboard on a regular basis and $11 \%$ snowboard at least once a season [16]. This represents a $1.1 \%$ increase since 2001. Active snowboarders number around 500,000 and 700,000 in Germany and Austria, respectively [9, 17].

The increased popularity of snowboarding is clearly reflected within the snow sports industry. Over the 2011/12 season, the US snow sports market conducted a record business volume of $\$ 3.3$ billion [11]. For example, products purchased at snow sports specialty stores in the US increased by $18 \%$ between the s $2006 / 07$ ( $\$ 1.7$ billion) and 2010/11 seasons ( $\$ 2.0$ billion). Online sales rose by $41 \%$ in the same time period to $\$ 652$ million in 2010/11 [11]. Snow sport accessories, including gloves and mittens, reached sales of approximately $\$ 1.2$ billion in 2010/11: an increase of $9 \%$ in units and $14 \%$ in dollars when compared with the previous season. Within the apparel-accessories category, gloves and mittens had sales of $\$ 125$ million and \$40 million, respectively [11]. However, the data did not distinguish between glove and mitten use by snow sports or between gloves/mittens with or without protective elements.

Overall, the risk of injuries while snowboarding is higher compared with alpine skiing [18-20]. A literature review found that the injury risk ranged from 0.8 to 8.0 injuries per 1,000 snowboard days [7]. Moreover, upper extremities are the most frequently reported injured body region $[7,19,21]$. Wrist or upper extremity injuries comprise 35-45 \% of all snowboarding injuries [19].

To minimize the incidence and severity of wrist injuries, several studies recommend wearing wrist protectors [7, 19, 21-28]. A meta-analysis on the effectiveness of wrist protectors in preventing wrist injuries showed that they reduced the risk of a wrist injury by $54 \%$ with no corresponding increase in the risk of shoulder injuries [19]. However, it was unclear if any specific wrist protector design or protective component provided increased safety function [19, 29]. Kim et al. [21] could not identify which wrist protector type or design was most protective. This is not surprising given the variety in design of wrist protectors currently on the market [30]. The design varies significantly, ranging from splint-like devices to gloves with integrated protectors (Fig. 1).

Wrist protectors designed for roller sports, such as inline skating, or for wrist injury rehabilitation were suggested to reduce wrist injuries in snowboarding [31, 32].

There is currently no standard available that dictates the requirements for wrist protectors in snowboarding to
Fig. 1 Variety of wrist protectors regarding concepts, technology, functions, and design features focused on protection characteristics; a $\operatorname{Red}^{\circledR}$ : short dorsal and palmar splint; palm padding; b Flexmeter ${ }^{\mathbb{B}}$ (FlexMP): dorsal and palmar splint; palm padding; c Level ${ }^{\circledR}$ : Biomextechnology positioned on the palmar side of the wrist (a)

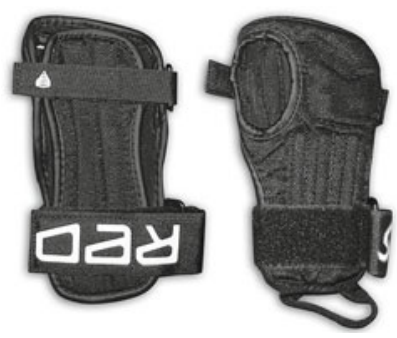

(b)

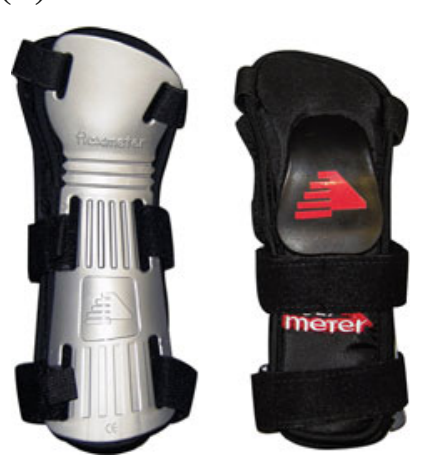

(c)

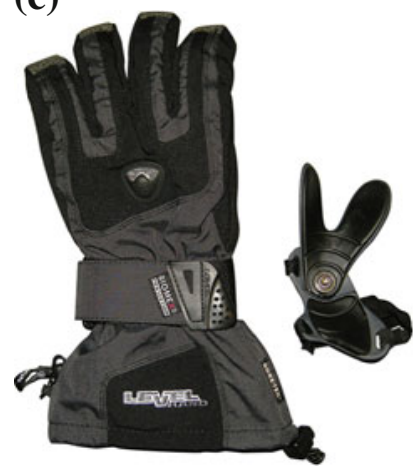


ensure minimum protective characteristics [30, 33, 34]. The ability of different wrist protector designs and the specific product requirements thought to be needed to reduce the incidence and severity of wrist and other upper extremity injuries are not well understood. Accordingly, the current snowboarding wrist injury evidence and the wide range of commercially available devices that claim to be wrist protectors, has led several research groups, sporting goods manufacturers, institutes for consumer protection, and public health organizations to argue towards a harmonized international standard regarding wrist protection in snowboarding [33-40].

\subsection{Objectives of the White Paper}

The objective is to evaluate the importance and necessity of a harmonized international standard to provide guidelines for minimum safety performance for all wrist protectors used in snowboarding. Moreover, we outline the general framework for a harmonized international standard.

The main objective of such a performance standard is to ensure the efficacy of the protector device in terms of cushioning and stability. This encompasses the reduction of impact forces and the prevention of terminal extension of the wrist joint during impact and such a standard should increase market transparency. Based on the certification testing and labeling requirements that would be adopted by governing bodies (e.g. countries, associations, municipalities, etc.), retailers and consumers alike would be able to differentiate between products that do and do not meet the minimum requirements. In addition, a minimum performance standard should assure that a wrist protector does not inadvertently increase the incidence and severity of other injuries, such as to more proximal sites on the upper extremity.

In the past, many sports equipment standards were often initially developed in individual countries, and then attempts were made to harmonize the different standards. In some cases, this has been quite successful, while in other cases the path to harmonization has proven very challenging.

ISO 5355 is an example of an international harmonized standard issued by the International Organization for Standardization (ISO) [41]. This international harmonized standard defines the requirements and test methods for alpine ski-boots. In contrast, there is no international harmonized standard for alpine ski and snowboard helmets. A variety of country- and regional-specific standards differ in basic performance requirements for shock absorption and the applied impact velocity for testing [42-45]. This leads to helmet that may differ in efficacy and performance, which can be confusing for consumers and challenging for manufacturers.
Given the lack of any known standard developed by any country or international body related to wrist protectors for winter sports, including snowboarding, there is an opportunity to develop and propose an international harmonized standard.

\subsection{Methods/procedure}

The International Society for Skiing Safety (ISSS) is a global, multidisciplinary organization that advances safety issues and injury care in snow sports through education and research and development in all related fields. The ISSS comprises ski area physicians, medical doctors, experts in biomechanics and engineering, epidemiologists, public and private safety organizations, winter sports industry, ski patrollers, attorneys, and sports enthusiasts. The ISSS convened a task force meeting to explore interest in creating a workgroup on the Development of an International Standard for Performance of Wrist Protectors at the 19th Congress on Ski Trauma and Safety, held in Keystone, Colorado, USA, in May 2011. Stakeholders representing the broad ISSS membership agreed that the scientific evidence related to the incidence of snowboarding wrist injuries and protective effect of wrist protectors provided a strong incentive to evaluate methods to reduce such injuries and that the development a standard test method for evaluating wrist protectors was warranted and should be pursued. The workgroup includes international representatives with diverse backgrounds in winter sports safety and standards development. The main objective of the workgroup is to evaluate existing standards related to wrist protection and personal protective equipment, to review published research related to wrist injuries and wrist protectors, and to explore the need for an international standard on wrist protection for snowboarding. As a first step, the workgroup recommended developing a White Paper to provide the basis for the workgroup's activities moving forward. This White Paper outlines a framework for the development of a new international standard for wrist protectors and therefore may serve as a common base for future discussions.

\section{Rationale for the development of a standard for wrist protectors}

\subsection{Wrist injuries in snowboarding}

Snowboarding is associated with a relatively high injury risk and the incidence of snowboarding-related trauma seems to be increasing [46]. Especially among 9-19-year olds, there is evidence that snowboarding injury rates are among the highest of all sports [47]. Among snowboarders, 
the wrist represents the most frequently injured body region and accounts for 19-28 \% of all injuries [20, 26, 48-50]. The injury rate of distal radial fractures is 0.31 per 1,000 snowboarder daily visits [51]. When compared with skiers, snowboarders have up to a 10 -fold increase in wrist injuries [50, 52, 53]. Because many statistics are solely based on the cases that received treatment onsite or in medical centres near skiing resorts, the true incidence of wrist injuries is possibly much higher due to underreporting, particularly for minor injuries [33]. It is assumed that up to $40 \%$ of alpine sport injuries are unreported since many injured snowboarders and skiers do not seek medical support from ski patrol at the resort $[26,48]$.

Wrist injuries can vary in severity, including contusions, sprains, distal radius/ulna fractures, carpal fractures, scaphoid fractures, or forearm fractures $[19,51]$. The most common wrist injury is a distal radius fracture $[31,50,54$, 55]. Sasaki et al. [56] interviewed injured snowboarders at a clinic in Japan and found that $54 \%$ of wrist injuries were distal radius fractures. In a prospective study at a primary emergency center, Matsumoto et al. [51] found that $86 \%$ of the 740 injured snowboarders sustained a wrist injury. Wrist sprains are also very common among snowboarders [7, 32].

Wrist injuries vary by sex, age and ability. Although male snowboarders made up approximately $62 \%$ of those sustaining wrist fractures, more snowboarders are males, and thus it appears that male and female snowboarders are equally as likely to sustain a wrist fracture [26, 51]. Children and beginner snowboarders have a high incidence of wrist injuries [19, 51, 55, 57]. One-third of injuries among beginners are to the wrist [48]. Kim et al. [53] recent study found that wrist injuries accounted for $20 \%$ of all adult and $38 \%$ of all children and adolescent snowboard injuries. A literature review found that $72 \%$ of all wrist injuries occurred within the first 7 days of learning to snowboard [48]. Dickson's prospective casecontrol study concluded that the most significant risk factors for a wrist fracture were age less than 16 years, being on holiday and being a first time participant [57]. In another study by Dickson et al. [58], novice snowboarders were at higher risk of a distal radius or a distal radius and ulna fracture than experienced riders. However, snowboarders with (self-declared) intermediate skill level also account for a large proportion of wrist injuries [51].

Because of the relatively high incidence of wrist injuries among children, wrist injuries involving growth plates are particularly worrisome $[19,59,60]$. This physeal injury pattern is unique to childhood, can be severe, and may result in arrested bone growth and deformity around the injury site [19, 61]. Physeal injuries appear to be especially pronounced during periods of rapid growth [62]. Idzikowski et al. [26] found that $9 \%$ of wrist fractures were physeal injuries and buckle fractures in skeletally immature riders. They reported that $50 \%$ of distal radius fractures occurred in the 10-19-year old age group [26]. Matsumoto et al. [51] diagnosed $2 \%$ of epiphyseal slipping of the distal radius among adolescent snowboarders. Owing to the enduring consequences of damage to the growth plates, the use of wrist protection devices are strongly recommended for children and adolescents [59].

In a cross-sectional study of 5,399 injured skiers and snowboarders, the highest percentage of wrist injuries occur on easy terrain $(17 \%)$ and inside terrain parks (10\%) [63]. In a recent study Kelly et al. [64] analyzed injuries sustained by snowboarders in a terrain park. The wrist represented the most commonly injured body region for both aerial $(19 \%)$ and non-aerial $(24 \%)$ features among snowboarders. These findings combined with the increasing popularity of terrain parks, warrants future attention [52]. Most epidemiological studies that investigated snowboard injuries as a function of location (e.g. inside vs. outside terrain parks) analysed only larger groupings of body regions, such as upper extremity injuries [65-67]. Thus far only Henrie et al. [68] report on wrist and hand injuries as a discrete anatomical location, but without differentiating between skiers and snowboarders. Their work highlights the importance of considering wrist injuries sustained in terrain parks, particularly with respect to young participants [68].

\subsection{Effectiveness, use and possible adverse effects of wrist protectors}

Several studies [25-27, 31, 32, 69] have shown that the risk of a wrist injury can be reduced by wearing wrist protection. A meta-analysis by Russell et al. showed that using wrist protectors while snowboarding reduced wrist fractures by as much as $50 \%$ (OR: $0.46 ; 95 \%$ CI: 0.35, 0.62) (18). Wrist protectors have been recommended as a valuable resource to prevent wrist injuries in snowboarding [26, $47,48,51,53,59,70-73]$, and some advocate that using wrist protectors should be strongly recommended for novice snowboarders, and perhaps a "no wrist guard = no snowboard" policy should be adopted [72]. Yet even with the observed effectiveness of wrist protectors and the ability to purchase or rent wrist protectors, the rate of wrist injuries has remained fairly constant at $19-28 \%$ of all snowboard related injuries [54].

One reason for the constant wrist injury prevalence may simply be that the use of wrist protectors remains relatively low, with worldwide estimates ranging from approximately $11-42 \%$ of interviewed snowboarders both on- and offpiste $[12,35,39,40,69,73-78]$. Importantly, the rate of 
wrist protector use was much lower, between 1 and $18 \%$, for wrist injured snowboarders [26, 72, 76, 79-81]. Engel and Langran reported that paediatric snowboarders who sustained wrist injuries while wearing wrist protection had a higher self-reported ability than injured riders not wearing wrist protectors [81]. Beginner and younger riders are the least likely to wear wrist protection while snowboarding $[35,76,77,80]$.

Bianchi et al. surveyed 3,791 snowboarders over six seasons in Switzerland to determine barriers to wrist protector use. The three most frequently mentioned explanations for non-use were: (1) wrist protectors are uncomfortable or even painful, (2) belief that wrist protectors may actually cause certain injuries, and (3) riders feel no need for wearing wrist protectors [35]. Dickson et al. found similar results: $20 \%$ of wrist-injured snowboarders surveyed who were not wearing wrist protection at the time of their injury acknowledged the potential benefits of wearing wrist protectors, but that they simply had not purchased a pair [78].

Figure 2 illustrates the results from annual statistics collected by the Swiss Council for Accident Prevention [33, 82, 83]. While snowboarding injury rates declined from 2003 to 2010, the rate of wrist injuries remained constant at approximately $10 \%$. In addition, wrist protector usage in Switzerland increased from $37 \%$ in 2003 to $42 \%$ in 2007 and then decreased to $27 \%$ by 2010, but the proportion/incidence of wrist injuries remained unchanged. This raises questions regarding the protective potential of the wrist protectors worn [33].

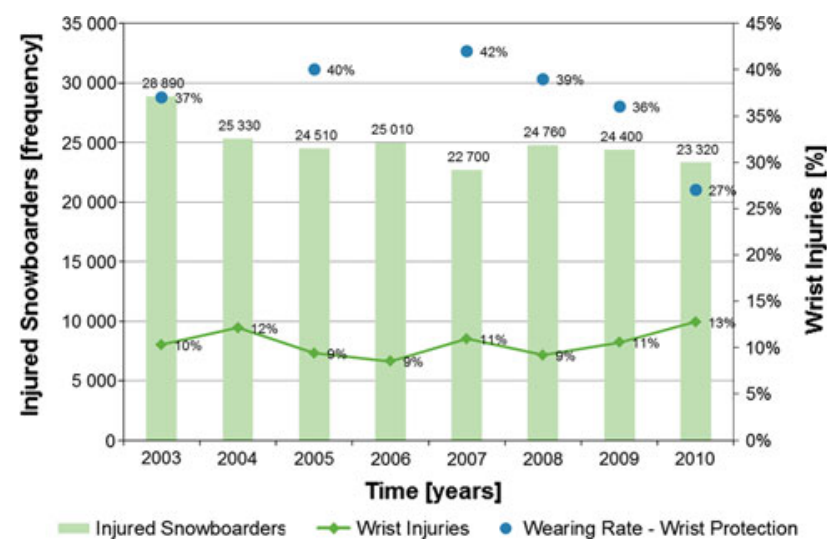

Fig. 2 Diagram shows the total of snowboarding injuries per year, the percentage of wrist injuries and the corresponding wearing rate of wrist guards as recorded by the bfu, Swiss Council for Accident Prevention [82, 83]. It should be noted that the total number of snowboarding injuries in Switzerland is extrapolated from representative samples of all age groups while information on specific wrist injuries is based on the group aged 17-64 only due to legal accident notification done by physicians and encoded in ICD 9 (based on Schmitt et al. [33], and supplemented by bfu)
Binet et al. performed field studies that showed that wrist protectors containing short stiff splints and possibly those worn on the palm side do not sufficiently protect against distal radius fractures [37, 74], and they posited that such constructions might actually contribute to wrist or forearm injuries [37]. In one study, all snowboarders who sustained distal radius fractures used wrist protection containing a short splint [74]. Dickson et al. found that the likelihood of sustaining a wrist fracture when wearing a short palm-side only protection was greater than any other wrist guard design $[37,57,76]$. The odds of a wrist injury when wearing a short, palm-side only design was 4.17 higher (95 \% CI: 0.89-19.52) when compared with short or long, dorsal or both sides design [76]. None of the injured snowboarders wearing a long, dorsal or bothsides design (sandwich construction) experienced a wrist fracture [57]. However, to date, there is no randomized controlled trial comparing the variety of wrist protector designs.

Several studies showed that the use of wrist protectors increase the risk of injuries to the elbow and shoulder joint [25, 84, 85]. However, only the study by Chow et al. [84] revealed a statistically significant lower incidence of shoulder injuries in snowboarders who did not use wrist guards $(p<0.05)$. In contrast, there are studies [25, 84, 85] and one literature review [47] that found no significant association between wrist protectors and increased risk of a shoulder, shoulder girdle, or arm injuries. O'Neill and Ronning et al. did not find an increase in more proximal or distal upper extremity injuries in snowboarders related to use of wrist protection [31, 32]. In a case-control study, Slaney et al. [72] found an association between wrist guard use and increased soft tissue elbow injuries, but not elbow fractures or dislocations. Hence, they recommend wearing wrist guards to reduce overall injury severity. Based on the clinical and radiological diagnosis, Pirie concluded that wrist injuries in snowboarders with wrist protectors were marginally less severe [39].

\subsection{Efficacy of snowboard wrist protectors}

Schmitt et al. [33] conducted a laboratory study to investigate the protective potential of wrist protectors for snowboarding. Since there is currently no standard that defines minimum performance requirements for wrist protectors in winter sports, the experimental set-up was chosen as closely as possible to the one prescribed in standard EN 14120 (inline skating) [86]. The test procedure consisted of two parts. A drop test was performed to analyze the damping behavior of the protectors (in the palm region). In addition, the stability of the protectors with regard to (hyper-) extension was investigated by a bending test using an artificial arm device. A total of 8 different 
designs of snowboard gloves (incl. protectors) and seven snowboard wrist guards were tested. In addition, three wrist protectors for inline skating were tested as reference. Two out of eight snowboard gloves fulfilled the requirements with regard to damping as defined in EN 14120. Three out the seven snowboard wrist guards and all inline wrist guards also passed this test. In the bending test approximately half of the products managed to limit wrist extension to the range as defined in the standard, but failed at a load level as recorded in a field test $[87,88]$ which was higher as defined in the standard. The results reveal that the performance of current products differs significantly and they suggest that several products offer very limited protection only.

Greenwald et al. [89] investigated the dynamic impact response of human cadaveric forearms using a wrist guard designed for snowboarding. Six pairs of forearms, one with and one without the wrist guard were impacted using a modified guillotine-type drop fixture placed over a force platform. The findings indicate that the wrist guard design may have some prophylactic effect at lower impact energies because they provide additional resistance to falling motion during initial loading. However, the tested wrist protector design reveals only a little effect in reducing loading rates at higher loads.

Müller et al. [90] compared four inline-skating wrist protectors by means of a drop-test and an artificial hand. The forces with and without wrist protectors were measured using a force moment sensor. The authors conclude that the protective effect of a wrist protector depends highly on the product that is used [90].

\section{Current situation of wrist protectors for snowboarding and related standards}

\subsection{Classification of current wrist protectors}

Currently, a wide variety of wrist protectors are commercially available (Fig. 3). Consumers can choose between two principal design concepts (Fig. 3). One is the "integrated protection concept" in which the protective elements are integrated within a glove. Another one is the "separated protection concept" where the protective elements are components of the wrist guard itself. This concept is similar to a brace or orthosis. This kind of wrist protector must be put on separately from the glove, i.e. first the protector is attached to the hand/forearm then the glove is placed on top.

Moreover, the "modular protection concept" is a combination of the integrated and the separated protection concept. Thus, it is not counted as a principle design concept. In this "hybrid" concept, the protective elements are separated or combined either in the glove or in the wrist guard (Fig. 4).

Independent of the principal concept for wrist protector, the reduction in impact forces and the guidance of movement to avoid terminal extension as well as certain radial and pronation movements of the wrist and forearm represent major functions of protector elements in snowboarding (Fig. 3). The reduction in impact forces can be realized through energy absorption, energy distribution or both. To absorb energy, usually damping elements are placed on the palmar site of the wrist/hand. Damping elements are usually not associated with the protector itself, but can be integrated

\begin{tabular}{|c|c|c|c|c|c|c|}
\hline \multirow{3}{*}{$\begin{array}{l}\text { Principal Concepts } \\
\text { (w.r.t. integration of } \\
\text { protection elements) } \\
\text { Function of protector } \\
\text { elements w.r.t. } \\
\text { injury mechanism }\end{array}$} & \multicolumn{6}{|c|}{$\begin{array}{l}\text { Integrated protection concept - Protection elements are integrated in glove } \\
\text { Separate protection concept - Protection elements are components of the wrist guard itself } \\
\text { (Modular protection concept - Protection elements are separated or combined integrated either in the glove and/or wrist guard) }\end{array}$} \\
\hline & \multicolumn{2}{|c|}{$\begin{array}{l}\text { Cushioning } \\
\text { Reduction of impact forces }\end{array}$} & \multicolumn{4}{|c|}{$\begin{array}{c}\text { Stability } \\
\text { Guidance of movement }\end{array}$} \\
\hline & Energy absorption & Energy distribution & \multicolumn{2}{|c|}{ Avoiding of wrist hyperextension (sagittal plane) } & \multicolumn{2}{|c|}{$\begin{array}{l}\text { Avoiding of excessive radial } \\
\text { deviation and pronation movement of the wrist/forearm } \\
\text { (frontal and transverse plane) }\end{array}$} \\
\hline Technology & $\begin{array}{l}\text { Damping elements } \\
\text { Placed on the palmar site of } \\
\text { the hand/wrist } \\
\text { - Palm padding } \\
\text { - Wrist padding }\end{array}$ & $\begin{array}{l}\text { Splint-like } \\
\text { elements } \\
\text { Placed on the palmar } \\
\text { site of the hand/wrist } \\
\text { - Palmar splint }\end{array}$ & $\begin{array}{l}\text { Splint elements } \\
\text { Position can be different: } \\
\text { - Palmar splint } \\
\text { - Dorsal splint } \\
\text { - Double splint (sandwich construction) }\end{array}$ & \multicolumn{2}{|c|}{$\begin{array}{l}\text { Specialty constructions } \\
\text { Different to conventional splints }\end{array}$} & $\begin{array}{l}\text { Guidance elements } \\
\text { Stabilisation of bone alignment }\end{array}$ \\
\hline $\begin{array}{l}\text { Differences in } \\
\text { design features }\end{array}$ & $\begin{array}{l}\text { - Material (e.g. foam } \\
\text { based or air-systems) } \\
\text { - Geometrical dimensions } \\
\text { especially material thickness } \\
\text { - Position and alignment }\end{array}$ & \multicolumn{2}{|c|}{$\begin{array}{l}\text { - Material (e.g. polymers, metal) } \\
\text { - Geometrical dimensions especially length of splint } \\
\text { - Position of splint (palmar/dorsal) } \\
\text { - Fixation of splint (depends on splint position) } \\
\text { - Placement and design of flex zone around the wrist to allow a } \\
\text { physiological range of motion } \\
\text { - Design of proximal and distal splint endings }\end{array}$} & \multicolumn{2}{|c|}{$\begin{array}{l}\text { e.g. ETWS - Engineered Textile Wrist } \\
\text { Protector from Simbex }\end{array}$} & $\begin{array}{l}\text { e.g. BIOMEX system embedded } \\
\text { in products from Level }\end{array}$ \\
\hline
\end{tabular}

Fig. 3 Wrist protection in snowboarding — classification of products, with respect to concepts, technology, function and design features focused on protection characteristics 
Fig. 4 Principle design/ construction of a wrist protector for snowboarding belonging to the modular protection concept (with permission from reusch ${ }^{\circledR}$ )

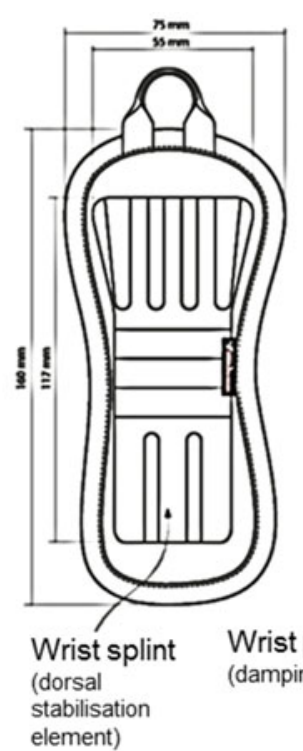

Palm paddings (damping element)

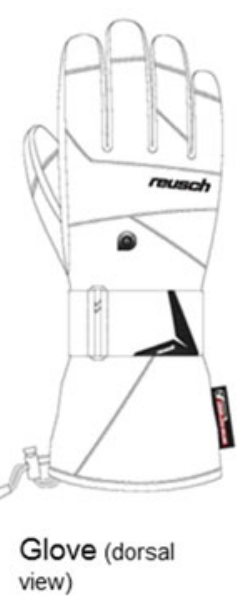

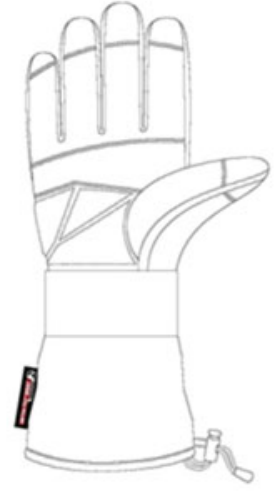

Glove with additional palm padding (palmar view)

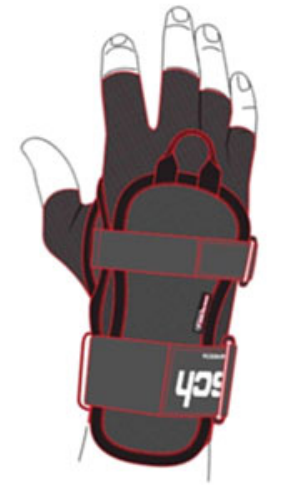

Wrist guard with wrist splint (dorsal view)

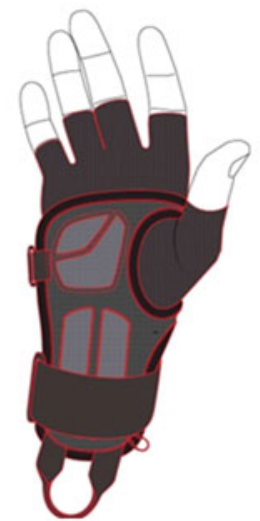

Wrist guard with wrist and palm paddings (palmar view) into the glove, e.g. by a specially designed area on the palm. For the distribution of impact forces, splint-like devices are also placed on the palmar site of the wrist/hand-region. Mostly, this function is integrated or combined within palmar placed splint elements which are used to avoid terminal extension of the wrist joint in the sagittal plane (Fig. 3). However, sometimes the splint is located on the dorsal side of the glove. Then the splint provides only stability by avoiding wrist hyperextension. Some wrist protectors use two splint elements which are typically positioned on the dorsal and palmar aspects of the hand. Furthermore, there are a few special designs which feature additional functions, such as a joint on the palmar side which allows or restricts certain rotations of the wrist and hand joints.

The size, shape and position of the cushioning and the stability elements as well as their mechanical and material properties can vary between products from different manufactures as well between products (different models) by the same manufacturer. However, these design features are typically fairly consistent between different products of the same model. Only a few brands adjust the size of the protection elements in relation to the size of the glove. Therefore, it can be assumed that the protective elements do not adapt with respect to age and body mass.

Consumers interested in buying a protector are confronted with this variety of designs without having the possibility (e.g. product information, labelling) to compare product performance. Introducing minimum performance requirements would thus ensure a minimum safety standard on which consumers can rely.

\subsection{Current standards related to wrist protectors}

Although there is no standard addressing wrist protectors in snowboarding, there is a standard for inline skating wrist protectors. EN 14120 defines drop tests (Fig. 5) as well as 
bending tests (Fig. 6) and associated performance criteria for inline skating wrist protectors [86]. The standard differentiates several classes of protectors related to the athlete's mass. Schmitt et al. [33] have shown that this standard can in principle also be applied to snowboarding protectors, but certain modifications would be required. For example, the artificial arm device used in the bending tests does not allow mounting fingered gloves in its current version (Fig. 6). Furthermore, all tests are performed at room temperature. Nonetheless, EN 14120 addresses many core features of wrist protectors, such as controlling wrist extension and managing impact energy, which are also relevant in snowboarding [86].

Other protective glove standards include EN 13594 (motorcycle gloves) [91], EN 1621 (elbow and forearm

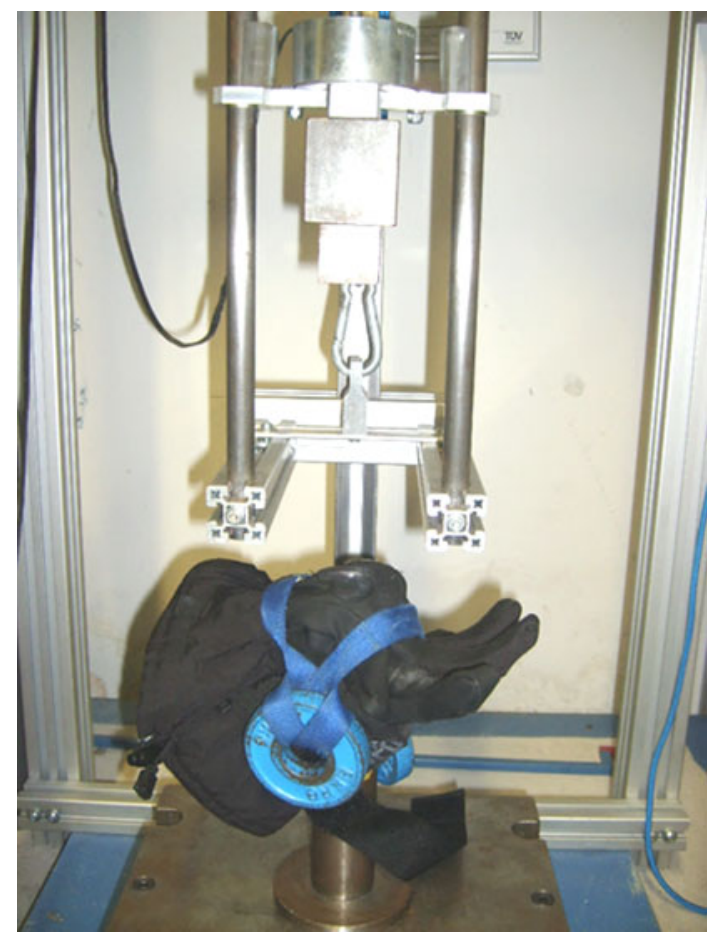

Fig. 5 Testing of impact performance/damping characteristics using a drop test apparatus protectors in motorcycling) [92], EN 420 (protective gloves in general) [93] and EN 16027 (protective gloves for goal keepers for association football [American soccer]) [94]. While the standard for motorcycle gloves includes similar testing methods as EN 14120 for inline skating wrist protectors (e.g. same drop test to investigate the damping performance), the standard for elbow/forearm protectors (EN 1621) assumes significantly higher impact energy. EN 16027 (goal keepers for association football [American soccer]) primarily addresses injuries to the fingers and focuses on glove padding [94]. More general aspects of gloves, such as the resistance of glove material to water penetration, are included in EN 420 [93]. General guidelines for personal protective equipment (PPE) are available which include requirements that are often related to comfort, climate aspects, sizing or abrasion resistance [86, 93-95]. Such aspects are important to ensure that a glove-like product also fulfills its functions. However, with regard to injury prevention, mechanical testing of the protectors to mimic the conditions where the protector will be used in should remain a key focus. In that respect, test devices and procedures based on the EN 14120 are already available which allow testing the performance of snowboarding wrist protectors in a laboratory setting. EN 14120 can therefore serve as a starting point for the development of corresponding standard [86].

\section{Current research on injury criteria focused on wrist and forearm injuries}

\subsection{Injury mechanism}

The majority of wrist injuries are consequences of falls [5, 20, 51, 56, 84, 96-99], particularly backward falls [26, 51, $54,100,101]$. Distal radius fractures are likely sustained when falling onto outstretched arms/hands and are observed in both backward and forward falls. According to Deady and Salonen [102], backward falls result in twice as
Fig. 6 Testing of stiffness/ stability characteristics: a schematic drawing of the bending test (adapted from EN 14120). To achieve a certain moment at the "wrist joint", the "hand" is loaded; b artificial arm device. Bottom original device (as prescribed in the standard), top modified version to allow fingered gloves to be mounted (a)

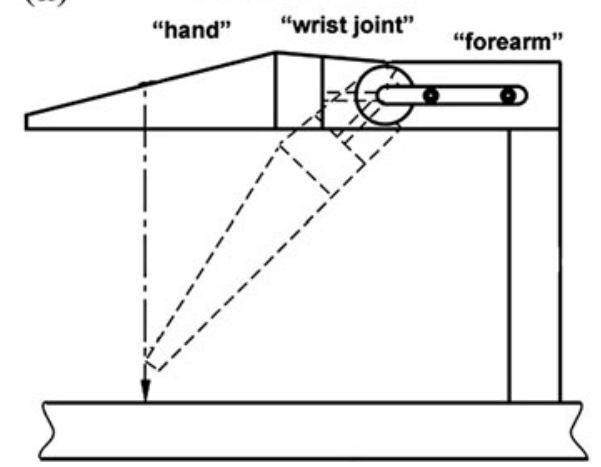

(b)

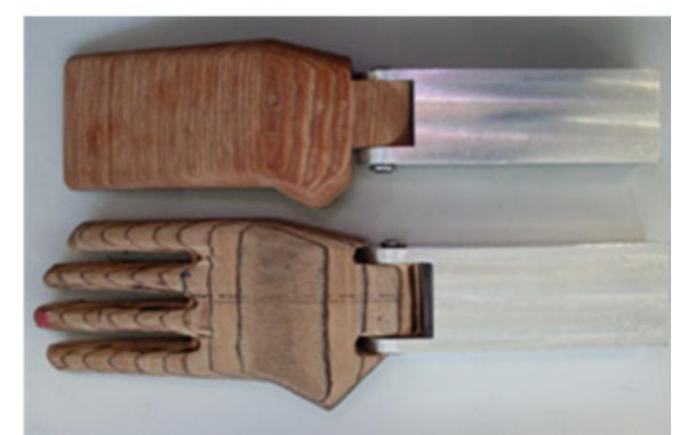




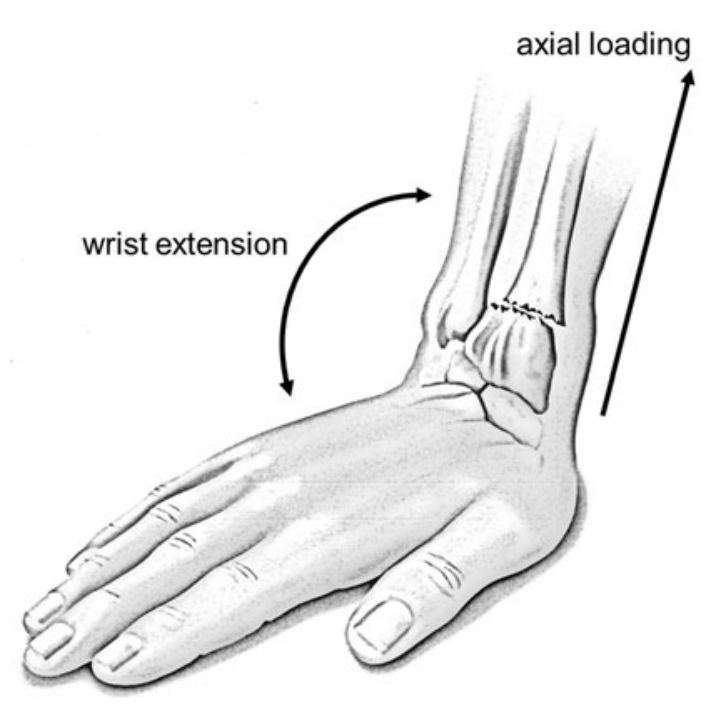

Fig. 7 Injury mechanism of a radial fracture attributable to compressive (axial) load applied to a hyperextended wrist at impact

many fractures as forward falls. The most common injury mechanism is described as a compressive load applied to a hyperextended wrist (Fig. 7) [103]. Moreover, radial deviation as well as a pronation alignment of the hand with respect to the forearm are suggested as influencing factors in wrist fractures [103].

\subsection{Injury threshold/injury criteria}

There are few experimental studies investigating wrist loading in snowboarding falls [19, 21]. Studies using mechanical surrogates or cadaveric arms found that a load of $2-2.5 \mathrm{kN}$ is needed to fracture the radius [33, 89, 104108]. Volunteer studies mimicking falls on the outstretched arm allow for generating parameters related to a fall (e.g. impact velocity, impact angle, impact forces, force distribution) [40, 109-117].

A recent study by Greenwald et al. used an instrumented glove to measure the forces that act on the wrist during normal riding (without any injury) [87, 88]. There were no injuries among the 128 analysed hand impacts. Backward falls resulted in statistically significantly higher maximum forces than forward falls (313 N vs. $225 \mathrm{~N})$ and demonstrated a non-significant trend for maximum wrist extension moment ( $p=0.091)$. Maximum wrist extension at impact was determined to be $80.2 \pm 15.8^{\circ}$ (SD) over all volunteers. Maximum extension moments (torque) of $10.8 \pm 11.3$ and $16.5 \pm 20.7 \mathrm{Nm}$ were recorded for young adults ( $\leq 17$ years) and adults ( $>17$ years), respectively. The influence of age was also observed with respect to maximum impact forces. Younger adults revealed lower impact forces $(222 \mathrm{~N})$ than adults $(314 \mathrm{~N})$. Among younger adults, there is a trend that beginners $(266 \mathrm{~N})$ have higher maximum impact forces compared with advanced riders (213 N). Maximum wrist extension at impact was determined to be $80.2 \pm 15.8^{\circ}$ (SD) over all volunteers [87, 88].

For comparison, the physiological range of wrist motion is $60-75^{\circ}$ for wrist extension and $60-82^{\circ}$ for wrist flexion [118-124]. Within a laboratory study mimicking snowboard falls, the average maximum wrist extension angle was for the left side $85^{\circ}$ and for the right side $82^{\circ}$, respectively [40]. These data are comparable with the values measured on slope [87, 88] and characterize the physiological limit of wrist extension.

These studies provide biomechanical data that characterize impact conditions during a fall. Together with known physiological limits regarding the wrist's range of motion, this data represent a reasonable basis for defining inputs and threshold values for developing standard test methodology.

\section{Mechanical requirements and safety parameters for wrist protection in snowboarding}

A snowboarding wrist protector standard should primarily address the prevention of radius fractures, the most common snowboarding injury. Based on the research to date, it is proposed that a wrist protector for snowboarding should prevent hyperextension of the wrist and to dampen the impact. These two different functions are already considered in many, but not all, commercially available protectors. Minimum requirements will be defined to ensure a certain level of protective capability in these two areas. Testing of products in a laboratory must be possible, i.e. the standard must consider practical aspects of testing and should be as simple, but appropriate, as possible. As shown by Schmitt et al., testing of wrist protectors using an artificial arm device for bending tests and a drop test set-up addressing damping is feasible [30, 33]. EN 14120 can serve as a starting point for defining a standard since it already includes two of the most relevant features. Test conditions must consider reasonable biomechanical threshold values based on the available data. Taking into consideration, different snowboarding environments, riding behaviour, age, skill level and the associated injury risk, it is suggested to develop different classes within the standard, e.g. for beginners, children, and different snowboard environments. Mechanical testing must consider the conditions encountered in snow sports, e.g. related to temperature and humidity. Furthermore, basic aspects related to comfort and handling should be included. This holds particularly true for wrist protectors that are not integrated into a glove. Many of these requirements are already considered in the existing standards related to gloves and PPE, and can serve as a starting point for these aspects of a wrist protector standard for snowboarding. 
Table 1 Initial considerations' concerning possible standard requirements for the two major performance variables "impact performance" and "bending stiffness" of wrist protectors in snowboarding

\begin{tabular}{|c|c|c|}
\hline & Impact performance (cushioning) & Bending stiffness (stability) \\
\hline Test equipment & $\begin{array}{l}\text { Drop test apparatus in which a guided mass falls onto a } \\
\text { test specimen on an anvil (Fig. 5) }\end{array}$ & $\begin{array}{l}\text { Artificial arm device with a low friction hinge joint } \\
\text { connecting the hand with the lower arm (Fig. 6) }\end{array}$ \\
\hline $\begin{array}{l}\text { Input variables (range of } \\
\text { body mass }>50 \mathrm{~kg} \text { ) }\end{array}$ & $\begin{array}{l}\text { Impact performance requirements for wrist protectors } \\
\text { (palm side): } 5 \mathrm{~J}\end{array}$ & $\begin{array}{l}\text { Moment of the wrist joint of the force to be applied: } \\
16 \mathrm{Nm}\end{array}$ \\
\hline $\begin{array}{l}\text { Performance criterions } \\
\text { (range of body } \\
\text { mass }>50 \mathrm{~kg} \text { ) }\end{array}$ & Max. peak force: $<3 \mathrm{kN}$ & $\begin{array}{l}\text { Max bending angle: }<80^{\circ} \\
\text { Min. bending angle }>30^{\circ} \text { (freedom of movement/ } \\
\text { comfort) }\end{array}$ \\
\hline Comments & $\begin{array}{l}\text { Impact energy of } 5 \mathrm{~J} \text { appears to be rather low as } \\
\text { compared to the findings from Schmitt et al. [33]. } \\
\text { However, } 5 \mathrm{~J} \text { might serve as starting point for } \\
\text { minimum impact energy, but conditions with higher } \\
\text { energy should be considered. } \\
\text { Beside body mass categories, segmentation with graded } \\
\text { input variables as well as performance criterions } \\
\text { regarding age and/or performance level should be } \\
\text { discussed }\end{array}$ & $\begin{array}{l}\text { EN } 14120 \text { (roller sports equipment) prescribes a } \\
\text { moment of } 3 \mathrm{Nm} \text { as a input variable and a movement } \\
\text { range between } 40^{\circ} \text { and } 55^{\circ} \text { to fulfill the performance } \\
\text { criterion }\end{array}$ \\
\hline References & $\begin{array}{l}\text { Schmitt et al. [33] } \\
\text { Schmitt et al. [40] } \\
\text { EN 14120:2003 + A1 [86] }\end{array}$ & $\begin{array}{l}\text { Greenwald et al. [87] } \\
\text { Greenwald et al. [88] } \\
\text { Schmitt et al. [33] } \\
\text { Schmitt et al. [40] } \\
\text { EN 14120:2003 + A1 [86] }\end{array}$ \\
\hline
\end{tabular}

Table 1 contains initial considerations concerning possible standard requirements for the two major performance variables "impact" and "stiffness" of wrist protectors in snowboarding. These initial thoughts are based on the previously published studies and represent just an extract of these findings and deductions.

\section{Conclusions}

A wrist protector standard for snowboarding is necessary for a number of reasons. There is clear evidence that a large proportion of snowboarding injuries are to the wrist, and specifically wrist fractures. The goal of the standard should primarily be aimed at preventing radius fractures but also preventing scaphoid fractures, forearm and ulna fractures as well as contusions and sprains, by ensuring minimum protective characteristics without increasing the risk of other adverse events. Wrist protectors should be designed to help prevent easing the compressive load to a hyper-extended wrist and to dampen the impact of a fall on the wrist, as well as protect against lacerations. In addition, basic aspects related to comfort and handling should be included. Presently, the wide variety of products in terms of protection capability means that not all wrist protectors are likely to perform similarly under the same input conditions. Consumers deserve guidance in choosing a product that meets minimum requirements. Manufacturers would also have guidance for product development and test methods to ensure a certain level of performance with respect to hyperextension prevention and dampening. Consequently, a standard for snowboarding wrist protectors should provide a benefit for all stakeholders.

The next step for the work group is to start working towards drafting a new standard. The ISSS conference in 2013 will serve as a platform for discussing the progress of the snowboarding wrist protector standard [125] and such a standard will potentially have a great impact on the snow sports industry and is expected to significantly contribute to a higher safety level of wrist protectors and ultimately reduce the incidence and severity of wrist injuries.

Acknowledgments The White Paper was founded and supported by the following institutions and companies which are engaged with the prevention of injuries in snow sports: bfu-Swiss Council of accident prevention, Switzerland; ARAG-Sports Insurance, Germany; Suva-Leisure-time safety, Switzerland; Reusch-Glove manufacturer, Italy; AGU-Working Group on Accident Mechanics, Switzerland; TÜV SÜD—Product Service GmbH, Germany

Conflict of interest The authors declare that they have no conflict of interest.

Open Access This article is distributed under the terms of the Creative Commons Attribution License which permits any use, 
distribution, and reproduction in any medium, provided the original author(s) and the source are credited.

\section{Appendix}

Contributors and members of the International Task Force on Wrist Protectors in Snowboarding:

Giannina Bianchi, MSc_-bfu, Swiss Council for Accident Prevention, Berne, Switzerland

Marc-Herve Binet, MD-Centre Medical D'Avoriaz, Avoriaz, France

Othmar Brügger, MSc—bfu, Swiss Council for Accident Prevention, Berne, Switzerland

Serge Darcy-Docmeter, Annecy, France

Naomi Engel, MB-ChB Emergency Department, Aberdeen Royal Infirmary, Aberdeen, Scotland

Bruce Jahnke-K2 Sports, Seattle, USA

Robert Johnson, MD-University of Vermont, Burlington, USA

Uwe Kersting, PhD—Aalborg University, Aalborg, Denmark

Jean-Dominique Laporte, MD—Medecins de Montagne, Montagne, France

Stefan Lehner, PhD-Technical University Munich, Munich, Germany

Jean-Francois Merino-Salomon S.A.S., Annecy, France

Nicola Petrone, PhD-University of Padova, Padova, Italy

Jake Shealy, PhD—Rochester Institute of Technology and GEAR Guidance Engineering, Rochester, USA

Florian Staudigl, Eng.-TÜV SÜD Munich, Munich, Germany

Yukio Urabe, MD—Hiroshima University, Hiroshima, Japan

Philippa Wadsworth, MB-ChB University Hospital of North Durham and Darlington Foundation Trust, Durham, UK

\section{References}

1. ABC of Snowboarding (2012) Snowboarding injuries: wrist fractures. Internet, ABC of Snowboarding, 22 Jun 2012

2. Van Tilburg C (2000) In-area and backcountry snowboarding: medical and safety aspects. Wilderness Environ Med 11:102108

3. Dann K, Kristen KH, Knoeringer M, Boldrino C, Nehrer S (2005) Snowboarden: Geschichte - Verletzungen - Risiken Materialneuigkeiten - Wettkampfbetreuung - Prävention. Der Orthopäde 34:433-440

4. Snowboarding history/Origin of snowboard (2012) Internet, ABC of Snowboarding, 22 June 2012
5. Dann K, Kristen K-H, Ring G (1995) Snowboarden: Geschichte, Ausrüstung, Verletzungen. Schulung und gutes Material beugen Verletzungen vor. TW Sport und Medizin 7:21-27

6. Dann K (2011) Snowboarding. In: Engelhardt M, Dorr A (eds) Sports orthopaedics. Elsevier, Official Manual of GOTS, pp 637-645

7. Russell K, Hagel B, Goulet C (2010) Snowboarding. In: Caine DJ, Harmer PA, Schiff MA (eds) Epidemiology of injuries in Olympic Sports. Blackwell Publishing, Oxford, pp 447-472

8. Hasler RM, Berov S, Benneker L et al (2010) Are there risk factors for snowboard injuries? A case-control multicentre study of 559 snowboarders. Br J Sports Med 44:816-821

9. Kusche H, Gutsfeld P, Bühren V (2010) Snowboarden. SportOrthopädie - Sport-Traumatologie 26:178-181

10. Canadian Ski Council (2009-2010) Canadian skier and snowboarder facts and stats, 2010. Canadian Ski Council, Collingwood

11. Snowsports Industries America—SIA research (2011) SIA snow sports market, intelligent report. 2011. Snowsports Industries America, McLean, VA, USA

12. Bianchi G, Michel FI, Brügger O (2012) The use of wrist guards by snowboarders in Switzerland. J ASTM Intl 19(STP 1553): $38-53$

13. Lamprecht M, Fischer A, Stamm H (2009) Sport Schweiz 2008: Das Sportverhalten der Schweizer Bevölkerung. Observatorium Sport und Bewegung Schweiz, 1-43. 2008. Magglingen, Bundesamt für Sport BASPO

14. Lamprecht M, Fischer A, Stamm H (2008) Sport Schweiz 2008: Kinder- und Jugendbericht. Bundesamt für Sport BASPO, Magglingen, pp 1-55

15. Lamprecht M, Fischer A, Stamm H (2009) Sport Schweiz 2008: Factsheets Sportarten. Observatorium Sport und Bewegung Schweiz, pp 1-51. Magglingen, Bundesamt für Sport BASPO

16. Ladner B (2012) Stabilität prägt die Sportlandschaft. Schweizer Sport \& Mode 3

17. Boldrino C (1998) Snowboardunfälle in Österreich: eine empirische Studie zur Analyse von Risikofaktoren beim Snowboarden. PhD Thesis. Wien, Universität Wien

18. Hagel BE, Goulet C, Platt RW, Pless IB (2004) Injuries among skiers and snowboarders in Quebec. Epidemiology 15:279-286

19. Russell K, Hagel B, Francescutti LH (2007) The effect of wrist guards on wrist and arm injuries among snowboarders: a systematic review. Clin J Sport Med 17:145-150

20. Sasaki K, Takagi M, Ida H, Yamakawa M, Ogino T (1999) Severity of upper limb injuries in snowboarding. Arch Orthop Trauma Surg 119:292-295

21. Kim S, Lee SK (2011) Snowboard wrist guards-use, efficacy, and design: a systematic review. Bull NYU Hospital Joint Dis 69:149-157

22. Abu-Laban RB (1991) Snowboarding injuries: an analysis and comparison with alpine skiing injuries. Can Med Assoc J 145:1097-1103

23. Bladin C, McCrory P (1995) Snowboarding injuries: an overview. Sports Med 19:358-364

24. Ganong RB, Heneveld EH, Beranek SR, Fry P (1992) Snowboarding injuries: a report on 415 patients. Phys Sportsmed 20:114-122

25. Hagel BE, Pless IB, Goulet C (2005) The effect of wrist guard use on upper-extremity injuries in snowboarders. Am J Epidemiol 162:149-156

26. Idzikowski JR, Janes PC, Abbott PJ (2000) Upper extremity snowboarding injuries: ten-year results from the Colorado snowboard injury survey. Am J Sports Med 28:825-832

27. Machold W, Kwasny O, Eisenhardt P et al (2002) Reduction of severe wrist injuries in snowboarding by an optimized wrist protection device: a prospective randomized trial. J Trauma 52:517-520 
28. Pigozzi F, Santori N, Di Salvo V, Parisi A, Di Luigi L (1997) Snowboard traumatology an epidemiological study. Orthopedics 20:505-509

29. MacDermid JC (2008) Do wrist guards decrease injuries among snowboarders? Clin J Sport Med 18:178-179

30. Schmitt K-U, Staudigl F, Michel FI (2011) Characterizing the performance of snowboard wrist protectors. In: Scher I, Greenwald R (ed) 19th International congress on ski trauma and skiing safety, book of abstracts. 1 May 2011

31. O'Neill DF (2003) Wrist injuries in guarded versus unguarded first time snowboarders. Clin Orthop Relat Res 409:91-95

32. Ronning R, Ronning I, Gerner T, Engebretsen L (2001) The efficacy of wrist protectors in preventing snowboarding injuries. Am J Sports Med 29:581-585

33. Schmitt K-U, Michel FI, Staudigl F (2011) Analysing the impact behaviour of recent snowboarding wrist protectors. IRCOBI Conference 2011, pp 51-61, Krakow

34. Staudigl F, Michel FI, Schmitt K-U (2011) Strategic considerations towards a standard for snowboard wrist protectors. In: Scher I, Greenwald, R (eds) 19th International Congress on Ski Trauma and Skiing Safety. Book of Abstracts. 2011. 1 May 2011

35. Bianchi G, Michel FI, Brügger O (2011) The use of wrist protection amongst snowboarders. In: Scher I, Greenwald R (eds) Book of abstracts of the 19th international congress on ski trauma and skiing safety. International Society for Skiing Safety, Keystone

36. Binet MH (2008) Snowboards, wristguards, terrain parks and avoiding injury. British Association of Sport and Excercise Medicine BASEM Spring Meeting, 6 April 2008

37. Binet MH, Laporte JD, Lamy D (2008) Prevention of snowboarding wrist injuries for teenagers. Poster präsentiert am: 2nd European conference on injury prevention and safety promotion. Making Europe a safer place, 9 Oct 2008

38. ISSS-International Society for Skiing Safety (2012) About the ISSS. Internet 2012. ISSS: International Society for Skiing Safety, 29 Jun 2012

39. Pirie T (2007) Snowboarders attending a ski field medical clinic with and without wrist guards: the rate and types of wrist injury seen in these groups. 17th International Symposium on Ski Trauma and Skiing Safety. Abstract Book, 13 May 2007

40. Schmitt KU, Wider D, Michel FI, Bruegger O, Gerber H, Denoth J (2012) Characterizing the mechanical parameters of forward and backward falls as experienced in snowboarding. Sports Biomechanics 11:57-72

41. International Organisation for Standardization (2006) Alpine ski-boots: requirements and test methods; ISO 5355: 2006. ISO ISO 5355: 2006. International Organisation for Standardization, Geneva

42. American Society for Testing and Materials (2002) Standard specification for helmets used for recreational snow sports; ASTM: F 2040-02. ASTM: F 2040-02. American Society for Testing and Materials, West Conshohocken

43. American Society for Testing and Materials (2003) Standard test methods for equipment and procedures used in evaluating the performance characteristics of protective headgear; ASTM: F 1446-03. ASTM: F 1446-03. American Society for Testing and Materials, West Conshohocken

44. Canadian Standards Association (CSA) (2008) Recreational alpine skiing and snowboarding helmets: CAN/CSA-Z263.1-08. Canadian Standards Association (CSA), Mississauga, ON

45. European Committee for Standardization (2007) Helmets for alpine skiers and snowboarders; EN 1077: 2007. EN 1077: 2007. European Committee for Standardization, Brussels

46. Hayes JR, Groner JI (2008) The increasing incidence of snowboard-related trauma. J Pediatr Surg 43:928-930
47. Hagel BE (2005) Skiing and snowboarding injuries. Med Sport Sci 48:74-119

48. Bladin C, McCrory P, Pogorzelski A (2004) Snowboarding injuries: current trends and future directions. Sports Med 34:133-139

49. Dohjima T, Sumi Y, Ohno T, Sumi H, Shimizu K (2001) The danger of snowboarding: a 9-year prospective comparison of snowboarding and skiing injuries. Acta Orthopaedica Scandinavia 44:436-439

50. Matsumoto K, Miyamoto K, Sumi H, Sumi Y, Shimizu K (2002) Upper Extremity Injuries in Snowboarding and Skiing: a Comparative Study. Clin J Sports Med 12:354-359

51. Matsumoto K, Sumi H, Sumi Y, Shimizu K (2004) Wrist fractures from snowboarding: a prospective study for 3 seasons from 1998 to 2001. Clin J Sport Med 14:64-71

52. Endres NK, Johnson RJ, Kim S, Ettlinger CF, Shealy JE (2007) Epidemiology of snowboarding and skiing injuries. In: Anonymous 17th international symposium on ski trauma and skiing safety, Abstract Book. Aviemore, Scotland

53. Kim S, Endres NK, Johnson RJ, Ettlinger CF, Shealy JE (2012) Snowboarding injuries: trends over time and comparisons with alpine skiing injuries. Am J Sports Med 40:770-776

54. Müller R, Brügger O, Mathys R, Stuessi E (2000) Snowboarding accidents. Sportverletz Sportschaden 14:121-127

55. Torjussen J, Bahr R (2005) Injuries among competitive snowboarders at the national elite level. Am J Sports Med 33:370-377

56. Sasaki K, Takagi M, Kiyoshige Y, Ogino T (1999) Snowboarder's wrist: Its severity compared with alpine skiing. J Trauma 46:1059-1061

57. Dickson TJ (2009) Risk factors in snowboarder's wrist fractures. In: Senner V, Fastenbauer V, Böhm H (eds) Proceedings of the 18th congress of the international society for skiing safety (ISSS). Technical University of Munich, Department of Sport Equipment and Materials, Garmisch-Partenkirchen, p 13

58. Dickson TJ, Trathen S (2011) Upper limb injuries in skiers and snowboarders. In: Scher I, Greenwald R (eds) 19th International congress on ski trauma and skiing safety. Book of Abstracts. 1 May 2011

59. Ashby K, Cassell E (2007) Injury in snow and ice sports. Hazard 66:1-19

60. Stine HA (2012) Growth Plate Fractures, 7 Feb 2007

61. Brown JH, DeLuca SA (1992) Growth plate injuries: salterHarris classification. Am Fam Physician 46:1180-1184

62. Caine D, DiFiori J, Maffulli N (2006) Physeal injuries in children's and youth sports: reasons for concern? Br J Sports Med 40:749-760

63. Henrie M, Thiese M, Chen Q, Powell A, Gee C, Willick S (2011) Descriptive epidemiology of wrist and hand injuries among skiers and snowboarders. In: Scher I, Greenwald R (eds) 19th International congress on ski trauma and skiing safety, book of abstracts, 1 May 2011

64. Russell K, Meeuwisse W, Nettel-Aguirre A, et al (2013) Characteristics of injuries sustained by snowboarders in a terrain park. Clin J Sport Med [Epub ahead of print]

65. Brooks MA, Evans MD, Rivara FP (2010) Evaluation of skiing and snowboarding injuries sustained in terrain parks versus traditional slopes. Inj Prev 16:119-122

66. Goulet C, Hagel B, Hamel D, Legare G (2007) Risk factors associated with serious ski patrol-reported injuries sustained by skiers and snowboarders in snow-parks and on other slopes. Can J Public Health 98:402-406

67. Moffat C, McIntosh S, Bringhurst J, Danenhauer K, Gilmore N, Hopkins CL (2009) Terrain park injuries. West J Emerg Med 10:257-262

68. Henrie M, Petron D, Chen Q, Powell A, Shaskey D, Willick S (2011) Comparison of ski and snowboard injuries that occur 
inside versus outside terrain parks. In: Scher I, Greenwald R (eds) 19th International congress on ski trauma and skiing safety, book of abstracts, 1 May 2011

69. Machold W, Kwasny O, Gässler P et al (2000) Risk of injury through snowboarding. J Trauma 48:1109-1114

70. Müller R, Brügger O, Mathys R, Stüssi E (2000) Snowboardunfälle. Sportverletz Sportschaden 4:121-127

71. Drkulec JA, Letts M (2001) Snowboarding injuries in children. Can J Surg 44:435-439

72. Slaney GM, Finn JC, Cook A, Weinstein P (2008) Wrist guards and wrist and elbow injury in snowboarders. Med J Aust 189:412

73. Made C, Elmquist L-G (1996) Downhill Skiing Injuries in Lapland, Schweden: a survey including alcohol monitoring and one year fellow-up. In: Mote CD, Johnson RJ, Hauser W, Schaff PS (eds) Sking trauma and safety: tenth volume, ASTM STP 1289. American Society for Testing and Materials, West Conshohocken, pp 98-103

74. Binet MH, Wadsworth P, Rowlands A (2011) Prospective study to compare efficacy of different designs of wrist protection for snowboarders. In: Scher I, Greenwald R (eds) 19th International congress on ski trauma and skiing safety, book of abstracts, 1 May 2011

75. Kroncke EL, Niedfeldt MW, Young CC (2008) Use of protective equipment by adolescents in inline skating, skateboarding, and snowboarding. Clin J Sport Med 18:38-43

76. Dickson TJ, Terwiel FA (2011) Snowboarding injuries in Australia: investigating risk factors in wrist fractures to enhance injury prevention strategies. Wilderness Environ Med 22:228235

77. Fuchs B, Gmünder C, Brügger O, Cavegn M, Walter M (2011) Personal protective gear in snow sport. Wearer behaviour and reasons for wearing. 16th International Symposium on Ski Trauma and Skiing Safety: abstract book, 26, 2005

78. Dickson TJ, Waddington G, Trathen S (2010) Upper limb injuries and protective equipment usage: a snapshot from australia. In: Müller E, Lindinger S, Stöggl T, Pfusterschmied J (eds) Science and skiing V: book of abstracts. Department of Sport Science and Kinesiology, University of Salzburg, Salzburg, Austria, p 13

79. Langran M, Selvaraj S (2002) Snow sports injuries in Scotland: a case-control study. Br J Sports Med 36:135-140

80. Made C, Elmqvist LG (2004) A 10-year study of snowboard injuries in Lapland Sweden. Scand J Med Sci Sports 14:128-133

81. Engel N, Langran M (2011) Implications of wrist guard use on wrist injuries in paediatric snowboarders: a retrospective cohort study. In: Scher I, Greenwald R (eds) 19th International congress on ski trauma and skiing safety, book of abstracts, 1 May 2011

82. Swiss Council for Accident Prevention (bfu) (2010) bfu-survey: use of protective equipment in skiing and snowboarding. bfu Swiss Council for Accident Prevention, Berne, 10 April 2012

83. Swiss Council for Accident Prevention (bfu) (2012) STATUS 2012: statistics on non-occupational accidents and the level of safety in Switzerland, Road traffic, sports, home and leisure. Berne, bfu

84. Chow TK, Corbett SW, Farstad DJ (1996) Spectrum of injuries from snowboarding. J Trauma 41:321-325

85. Fischler L, Röthlisberger M (1996) Ski- und Snowboardunfälle im Vergleich: ein aktueller Überblick aus dem Skigebiet von Arosa (1988/89 bis 1994/95). Schweizerische Rundschau für Medizin 85:777-782

86. European Committee for Standardization (2003) Protective clothing - Wrist, palm, knee and elbow protectors for users of roller sports equipment, Requirements and test methods; EN
14120:2003 + A1. EN 14120:2003 + A1. 2007. European Committee for Standardization, Brussels

87. Greenwald R, Calabro S, Thomas N, Michel FI (2011) An instrumented glove to measure wrist biomechanics during snowboard falls. In: Scher I, Greenwald R (eds) 19th International congress on ski trauma and skiing safety, book of abstracts, 1 May 2011

88. Greenwald RM, Simpson FH, Michel FI (2013) Wrist biomechanics during snowboard falls. In: Proceedings of the Institution of Mechanical Engineers, Part P: Journal of Sports Engineering and Technology (accepted)

89. Greenwald RM, Janes PC, Swanson SC, McDonald TR (1998) Dynamic impact response of human cadaveric forearms using a wrist brace. Am J Sports Med 26:825-830

90. Müller I, Vogiatzis M, Wiese K et al (2003) Biomechanische Untersuchung zur Effektivität von Handgelenkprotektoren für das Inline-Skating. Sportverletz Sportschaden 17:80-83

91. European Committee for Standardization (2002) Protective gloves for professional motorcycle riders: requirements and test methods; EN 13594:2002. EN 13594:2002. European Committee for Standardization, Brussels

92. European Committee for Standardization (1997) Motorcyclist's protective clothing against mechanical impact-Part 1: Requirements and test methods for impact protectors; EN 1621-1:1997. EN 1621-1:1997. European Committee for Standardization, Brussels

93. European Committee for Standardization (2009) Protective gloves-general requirements and test methods; EN 420:2003 + A1. EN 420:2003 + A1. European Committee for Standardization, Brussels

94. European Committee for Standardization (2011) Protective clothing-Gloves with protective effect for association football goal keepers; EN 16027. EN 16027. European Committee for Standardization, Brussels

95. Anonymous (1989) Richtlinie des Rates vom 21. Dezember 1989 zur Angleichung der Rechtsvorschriften der Mitgliederstaaten für persönliche Schutzausrüstungen (89/686/EWG). Amtsblatt der Europäischen Gemeinschaften Nr. L 399/18

96. Campell LR (1995) Snowboardunfälle: Multizentrische schweizerische Snowboardstudie 1992/93. bfu-Report 29. Schweizerische Beratungsstelle für Unfallverhütung, Bern

97. Dann K, Kristen K-H, Ring G (1995) Über den Wandel des Verletzungsmusters beim Snowboarden in Abhängigkeit vom Fahrkönnen. Sport-Orthopädie - Sport-Traumatologie 11:235-240

98. Davidson TM, Laliotis AT (1996) Alpine skiing injuries: a nineyear study. Western J Med 164:310-314

99. Ferrera PC, McKenna DP, Gilman EA (1999) Injury patterns with snowboarding. Am J Sports Med 17:575-577

100. Davidson TM, Laliotis AT (1996) Snowboarding injuries: a four-year study with comparison with alpine ski injuries. Western J Med 164:231-237

101. Machold W, Kolonja A, Kwasny O, Fuchs M (1999) Verletzungsrisiken beim Snowboarden. Sportverletz Sportschaden 13:1-7

102. Deady LH, Salonen D (2010) Skiing and snowboarding injuries: a review with a focus on mechanism of injury. Radiol Clin North Am 48:1113-1124

103. Whiting WC, Zernicke RF (2008) Biomechanics of musculoskeletal injury, 2nd edn. Human Kinetics, Champaign

104. Moore MS, Popovic NA, Daniel JN, Boyea SR, Polly DW (1997) The effect of wrist brace on injury patterns in experimentally produced distal radial fractures in a cadaveric model. Am J Sports Med 25:394-401

105. Moore DC, Staebler MP, Greenwald RM, Akelman E, Weiss AC (2000) Wrist guards reduce impact-generated bone strain in 
the distal radius. Poster presented at, 46th Annual Meeting, Orthopedic Research Society, March 12-15, 2000, Orlando, FL

106. Lewis LM, West OC, Standeven J, Jarvis H (1997) Do wrist guards protect against fractures? Ann Emerg Med 20:766-769

107. Kim KJ, Alian AM, Morris WS, Lee YH (2006) Shock attenuation of various protective devices for prevention of fall-related injuries of the forearm/hand complex. Am J Sports Med 34:637-643

108. Staebler MP, Moore DC, Akelman E, Weiss APC, Fadale PD, Crisco JJ (1999) The effect of wrist guards on bone strain in the distal forearm. Am J Sports Med 27:500-506

109. Chiu J, Robinovitch SN (1998) Prediction of upper extremity impact forces during falls on the outstretched hand. J Biomech 31:1169-1176

110. DeGoede KM, shton-Miller JA, Schultz AB, Alexander NB (2002) Biomechanical factors affecting the peak hand reaction force during the bimanual arrest of a moving mass. J Biomech Eng 124:107-112

111. DeGoede KM, shton-Miller JA (2002) Fall arrest strategy affects peak hand impact force in a forward fall. J Biomech 35:843-848

112. Lo J, McCabe GN, DeGoede KM, Okuizumi H, Ashton-Miller JA (2003) On reducing hand impact force in forward falls: results of a brief intervention in young males. Clin Biomech (Bristol, Avon) 18:730-736

113. Burkhart TA, Andrews DM (2010) The effectiveness of wrist guards for reducing wrist and elbow accelerations resulting from simulated forward falls. J Appl Biomech 26:281-289

114. Choi WJ, Robinovitch SN (2011) Pressure distribution over the palm region during forward falls on the outstretched hands. J Biomech 44:532-539
115. Hwang IK, Kim KJ, Kaufman KR, Cooney WP, An KN (2006) Biomechanical efficiency of wrist guards as a shock isolator. J Biomech Eng 128:229-234

116. Hwang IK, Kim KJ (2004) Shock-absorbing effects of various padding conditions in improving efficacy of wrist guards. J Sports Sci Med 3:23-29

117. Tan JS, Eng JJ, Robinovitch SN, Warnick B (2006) Wrist impact velocities are smaller in forward falls than backward falls from standing. J Biomech 39:1804-1811

118. American Academy of Orthopaedic Surgeons (1965) Joint motion: method of measuring and recording. American Academy of Orthopaedic Surgeons, Chicago

119. Behnke RS (2012) Kinetic anatomy, 3rd edn. Human Kinetics, Champaign

120. Boone DC, Azen SP (1979) Normal range of motion of joints in male subjects. J Bone Joint Surg Am 61:756-759

121. Brumfield RH Jr, Nickel VL, Nickel E (1966) Joint motion in wrist flexion and extension. South Med J 59:909-910

122. Rettig AC (1998) Elbow, forearm and wrist injuries in the athlete. Sports Med 25:115-130

123. Ryu JY, Cooney WP III, Askew LJ, An KN, Chao EY (1991) Functional ranges of motion of the wrist joint. J Hand Surg Am 16:409-419

124. Werner SL, Plancher KD (1998) Biomechanics of wrist injuries in sports. Clin Sports Med 17:407-420

125. International Society for Skiing Safety (2012) 20th Congress of the International Society for Skiing Safety, Internet. International Society for Skiing Safety, 26 Sept 2012 